\title{
FEATURE
}

\section{Promoting Library Reference Services to First-Year Undergraduate Students What Works?}

\author{
Karen Sobel \\ Karen Sobel is Reference and \\ Instruction Librarian, Auraria Library, \\ University of Colorado-Denver. \\ Submitted for review January 30, 2008; \\ revised and accepted for publication \\ May 9, 2008.
}

Most academic libraries have limited budgets for promoting their reference services. Understanding which promotions best reach current and potential patrons is crucial to budgeting funding, as well as time, effectively. This article describes a study that sought to answer three questions: (1) What percentage of first-year undergraduate students are aware of reference services? (2) What percentage of first-years seek information from reference librarians? (3) Through which media are first-years comfortable communicating with reference librarians? To answer these questions, the researcher surveyed 237 first-years during their first semester at the University of North Carolina at Chapel Hill (UNC). Awareness varied greatly by media (i.e., in-person, chat, and telephone reference services). Approximately 35 percent of students reported already having used the UNC University Libraries' reference services. About 69 percent of students preferred face-to-face options over virtual or voice media. Strong trends related to peers' and educators' recommendations of reference services also emerged.

Reference \& User Services Quarterly, vol. 48, no. 4, pp. 362-371

(c) 2009 American Library Association. All rights reserved.

Permission granted to reproduce for nonprofit, educational use.

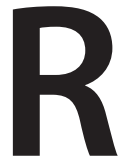

eference and instructional departments at academic libraries often promote their services to undergraduate students through numerous methods. A few popular examples include distributing flyers at freshman orientation, placing links to chat reference services on the library's home page, and hanging a "Questions?" sign above the reference desk with the hope that students will come. Yet few libraries assess which efforts actually influence those students who choose to use reference services. The purpose of this study is to explore the motivations of first-year students who reported having reference interactions at the University of North Carolina at Chapel Hill (UNC). While several other factors, such as professors requiring the use of the reference desk for an assignment, proved more influential, the instruction-session scenario is the most influential factor over which librarians have direct control. Most currently available research evaluates only a single method of promotion. This study measures and compares the effectiveness of all the methods available at a single university's libraries.

In fall 2006, a 3,816 students began their first year of college at UNC. ${ }^{1}$ The reference desk at UNC's R. B. House Undergraduate Library (generally referred to as the Undergraduate Library), primarily used by the university's first- and second-year undergraduate students, recorded 10,757 questions received during the 2006-07 school year. ${ }^{2}$ This figure included ques- 
tions asked through all means available at that library, including face-to-face, instant messenger, and telephone interactions.

In preparation for this study, UNC's reference librarians identified seven ways their services were promoted:

- Verbal publicity during library instruction sessions

- "Ask-a-Librarian" links on UNC University Libraries' webpages

- Participation in first-year orientation

- Professors requiring the use of reference services for class assignments

- Recommendations by peers

- Positive experiences using reference desks at other libraries

- Students noticing the reference desk at a UNC library

Why is it important to compare the effectiveness of all these promotional methods? There are two main reasons. First, knowing which methods of promotion truly affect students' choices to visit the reference desk can help librarians encourage students to visit the desk sooner. More specifically, when librarians understand how to reach out to freshmen, they can encourage more students to use the reference desk throughout their college careers, right from the start. Second, most academic libraries have less funding for promotion than their staff would like. Knowing which methods of promotion best reach new users-an important audience-can help librarians maximize the effect of their promotional dollars.

\section{BACKGROUND}

The latest available figures show nearly seventeen thousand undergraduates (nearly all full-time) and about eleven thousand graduate students enrolled at UNC. ${ }^{3}$ Undergraduate standards for admission are rigorous, with a 34 percent acceptance rate. Peterson's Four-Year Colleges 2008 cites an average high school GPA of 4.0 for students admitted as first-year undergraduates at the university. ${ }^{4}$ Moreover, UNC prides itself on promoting diversity. Approximately 22 percent of its students are minorities, and 17 percent of students come from 48 states outside of North Carolina and 111 foreign countries. $^{5}$

Upon entering UNC as undergraduates, students are placed in English composition courses with one of four possibilities. Students may be instructed to take English 100, English 101, English 102, or test out of the English composition requirement completely. Placement is determined by SAT scores, high school advanced placement coursework, and a placement test taken during orientation. The vast majority of UNC's undergraduate students are placed in English 101. Students who place into English 100 or 101 must take all the subsequent courses in the series.

The English department requires that all teaching assistants bring their English 101 classes to the library for at least one instruction session. ${ }^{6}$ During all sessions, students bring an assignment to work on. Library staff (including librarians and graduate students in the university's Master of Science in Library Science program) provide instruction on several relevant library resources, then provide assistance during guided work time.

\section{LITERATURE REVIEW}

Although the question of how first-year college students choose whether to use reference services sounds simple, it actually involves many complex factors. For instance, in the case of students, the factors may include their previous experience with libraries and librarians, their academic courses and goals, and their levels of library-related anxiety. For librarians, this question involves subtleties of their personal interactions with students, their drive to learn and use new technologies, and endless time and patience. For an academic library as an organization, factors involve ties between the library and various academic departments, funding for staff and training, and the range of images that the university projects. The following literature provides background on these complex, interlocking elements.

Familiarity with the concept of library anxiety helps librarians better understand students' reasons for using or not using reference services. Sharon L. Bostick's Library Anxiety Scale has become a standard for the quantification and discussion of anxiety and discomfort among library patrons. ${ }^{7}$ Along with colleagues Anthony J. Ongwuegbuzie and Qun G. Jiao, Bostick has further explored library anxiety through personality theories designed by psychologists. One of the aspects of their research most relevant to this study is the concept of state anxiety versus trait anxiety. ${ }^{8}$ In very basic terms, state anxiety is anxiety resulting from the situation a person is currently in. Trait anxiety is a tendency to feel anxious in many, varied situations. ${ }^{9}$

Another relevant piece of Bostick's work with the Library Anxiety Scale is her list of five dimensions of library anxiety. The dimensions are "barriers with staff, affective barriers, comfort with the library, knowledge of the library, and mechanical 
barriers." ${ }^{10}$ The first two factors relate most strongly to the questions involved in this study.

Statistics from various studies on library anxiety provide additional impetus for this study. For instance, Joanne E. Callinan's 2005 study at University College Dublin revealed that 56 percent of students prefer to ask library-related questions of their friends rather than librarians. ${ }^{11}$ What if librarians were able to help all those students build greater comfort levels with the library? Such outreach could vastly increase the use of reference services and prove to be a huge academic benefit to students.

Librarians have written a massive body of literature on the promotion of library services in the forms of both case studies and theory. Antony Brewerton has integrated his theories on public relations and advertising with applicable cases from his own university, Oxford Brookes, in the United Kingdom. Reference services are one of the main aspects that he has studied. One of Brewerton's major points about promotion of reference services is that librarians tend to imagine their patrons as a "captive audience," so no matter the quality of promotional efforts, these patrons will find and use the services out of necessity. ${ }^{12}$ However, in reality, some patrons use them well, some use them poorly, some never find the services, and some use alternatives.

Brewerton has also emphasized the need to reach out to new patrons-in his case, mostly first-year students and new faculty-and get them involved with the library early on. ${ }^{13}$ In his advertising theories, Brewerton emphasizes creating humorous and often edgy advertisements, such as a poster reading "Wanted: library virgins ( . . . to go on library tours)." ${ }^{14} \mathrm{UNC}$ has far more conservative philosophies, and this study aims to explore indirectly the efficacy of various promotional methods by quantifying the effects of these strategies. Typically, UNC University Libraries uses a professional yet often playful tone in their advertising materials. Seasoned staff have informed this researcher that hypothetical ads similar to Brewerton's would likely be deemed inappropriate by some faculty and library staff at UNC.

Simply luring students into the library in the first place is an important phase of advertising. Numerous recent articles, such as Vondracek's "Comfort and Convenience? Why Students Choose Alternatives to the Library," suggest that students tend to come to the library for reasons other than consulting a reference librarian. ${ }^{15}$ Vondracek and her colleagues conducted a variety of focus groups and surveys with 3,227 undergraduate "frequent," "infrequent," "moderate," and "nonusers" at Oregon State University's Valley Library. The atmo- sphere of the library, as well as other potential study spaces, proved to be a major theme in students' process of deciding where to study. Interestingly, during focus groups comparing "frequent" and "infrequent" or "nonusers," even frequent users proved to be relatively unaware of librarians' capabilities. Notes Vondracek, "One student was unaware that the librarians had subject specialties and suggested that we create a list of the librarians and specialties, which we do provide on our Web site, although it may be difficult to find." ${ }^{\prime 16}$

Determining needs and actual use across the undergraduate career are two crucial components of evaluating the effectiveness of library services for undergraduates. The issue of "needs" affects the planning of library services in many important ways. Richard M. Dougherty's writing on "userresponsive research libraries" suggests that services and methods of retrieving information must be designed around users' "actual abilities."17 Granted, his cohort is made up of more sophisticated researchers and scholars, but the point remains valid for meeting needs of all patrons.

Experienced reference librarians discuss reasons for use or nonuse of reference services not only as a result of library anxiety but as a result of motivations. Marjorie E. Murfin details relevant theories of motivation as discussed by Brehm and Self in $1989 .{ }^{18}$ Academic majors and disciplines also play large roles in motivating reference desk use. Murfin notes that most general reference librarians receive far more questions in the social sciences and humanities than in the sciences and technology. She suggests that science and technology courses require less library research. ${ }^{19}$ This statement may be expanded with the idea that science and technology students may become used to patterns of study and research that do not involve library use, starting relatively early in their careers. Encouraging them to use the library during early, common classes such as composition may help to foster more library-positive patterns.

Murfin explains that "the reference department is, in a sense, the expert on library users, on their knowledge, abilities, problems, and responses." 20 Available research describes relatively few methods of advertising specifically to first-year students. The most popular are bibliographic instruction sessions, optional or required sessions during orientation, online instructional materials, special first-year help stations or staff, and special activities such as scavenger hunts.

Connaway, Radford, and Dickey's research on the nonuse of virtual reference services in academic and public libraries provides useful commentary on the nonuse of both virtual and in-person 
reference services. Reasons for using (or not using) reference services covered in their surveys and focus-group questions closely relate to those covered in this study. Interestingly, both teens and graduate students (the two populations covered in Connaway, Radford, and Dickey's study) indicated that developing a positive working relationship with a particular librarian would be of great help to their research. ${ }^{21}$ Some nonusers who were aware of virtual reference services were concerned that they could not build a lasting relationship with a librarian online, or that they could not control which librarian they contacted through virtual media. ${ }^{22}$ However, in their survey of 184 nonusers of virtual reference services, the researchers found that a simple lack of awareness of services' existence was the most influential cause of nonuse, affecting 73 percent of survey participants. ${ }^{23}$ Being aware of such crucial library services could raise students' interest in reference services and the library in general.

Byerly, Downey, and Ramin discuss the challenges of spreading basic library knowledge at large universities, where students choose from an immense variety of courses and may end up having little bibliographic instruction. Among the very few courses that most students take are two levels of composition. ${ }^{24}$ Many authors have discussed first-year composition courses as rare opportunities to make basic bibliographic instruction reach the majority of students. The three aforementioned authors list the following methods for seeking research help as parts of their standard composition class bibliographic instruction: "showing them the reference desk, phone numbers for the reference desk, and how to e-mail the virtual reference desk." ${ }^{25}$ They also eloquently note that "one of the primary goals of our library instruction sessions is to impress upon students the importance of making use of the most valuable resource in the library, the librarians. ${ }^{26}$ Recent research shows that libraries and librarians could perform significantly better in this area. Callinan's research found that, in her library, 67 percent of first-year students and 96 percent of final-year students list their friends, rather than librarians, as their main source of information on how to use the library effectively. ${ }^{27}$

\section{OBJECTIVES}

This research explored three related questions, which were based on staff observations at the Undergraduate Library:

1. What percentage of first-year undergraduate students are aware of reference services?
2. What percentage of first-years seeks information from reference librarians?

3. Through which media are first-years comfortable communicating with reference librarians?

The answers to these questions can help staff tailor future promotional efforts to better reach new students and perhaps save money. They can also suggest ways that other academic libraries can shape their own promotional efforts and guide future related research.

\section{METHOD}

\section{Sample}

This researcher began by surveying fourteen randomly chosen sections of the English 101 class at UNC. ${ }^{28}$ Each section had nineteen available seats. Instructors of these sections were sent a request for participation, plus explanatory information, via e-mail. Originally, the researcher had planned to survey only one section per instructor. However, several instructors kindly offered the opportunity to survey each of two sections. After determining that there would be little influence on validity, the researcher accepted these offers.

Since most first-year students (around 85 percent) take English 101, the subjects' racial, ethnic, gender, age, and socioeconomic status should closely mirror those of the UNC student body as a whole. Although students were not asked to note their age, nearly all students appeared to be of traditional age (between approximately seventeen and nineteen). Students under age eighteen were instructed not to complete the survey for legal reasons.

A total of 230 subjects (97 percent) were in their first year of undergraduate education. Of the survey participants, 123 (51.9 percent) were male, and 114 (48.1 percent) were female. This differs significantly from UNC's overall male-female ratio of 41 to $59 .{ }^{29}$ The College Board's (administrator of the SAT) data on UNC students' performance on the SAT writing section shows female students outperforming males since the writing section was first offered in 2006. Both years, women outperformed men by 11 points (492 to 502 and 489 to 500). ${ }^{30}$ Since SATs are used in placement, this may relate strongly to the differences in gender ratios in English 101 and at UNC overall. More females may have placed into English 102 or out of composition entirely.

\section{Survey}

This survey was not pretested in a traditional sense. The researcher finished designing the sur- 
vey in early summer 2007. Because sections of English 101 offered over the summer semester are many weeks shorter than sections held in the fall, students would likely have had significantly different rates of interaction with librarians than the intended subjects. Thus the researcher prepared the study by gathering critiques from several professors in the School of Information and Library Science and the researcher's colleagues at the Undergraduate Library.

The survey was designed to take a fairly direct approach at answering each of the three questions detailed in the "Objectives" section. It also directly gathered demographic information. Finally, it gathered a few pieces of information indicating students' attitudes toward reference services and librarians in general. The survey's text is available in the appendix.

The survey was administered during the second and third weeks of September 2007. Gathering information so early in students' first semester allowed the researcher to explore the immediate effects of students' early interactions with librarians and library promotional materials. The survey was provided on paper so that all students had the opportunity to participate (i.e., no laptop problems). The researcher gave the survey during the last five minutes of regular class time in the sections' usual classrooms. Some sections had already visited the library, and some had not.

\section{Data Analysis}

After collecting data from all fourteen sections of English 101, the researcher entered the data values into SPSS software. Once all of the data was entered, raw totals provided interesting insight. Thus much attention is focused on these numbers. Staff at UNC's Odum Institute for Research in Social Science provided guidance on the analysis for each desired pairing of variables. They noted that, although chi-square tests showed that some of the important pairings were not statistically significant, the relatively large sample size and distinct patterns in the data made them meaningful. These combinations of data are shown as graphs that are based on cross-tabulations performed using SPSS software.

\section{RESULTS}

\section{Demographics}

As previously stated, 123 (51.9 percent) of the subjects were male while 48.1 percent were female. A total of 230 (97 percent) were first-year students. Students who were not first-years were not asked to further specify their class standing. Only 7 out of 237 students (1.3 percent) reported being in their second year of school or beyond. This division did not significantly affect any statistics. Thus these students have been grouped with the first-years for all analyses and discussion.

\section{Gender}

One question that arose early in this study was the relationship between gender and preference for in-person interactions with librarians. Popular culture and numerous reputable sources discuss differences in communication styles between males and females. Academic library staff often display an imbalance of gender.

However, results from this study do not show a significant relationship between gender and comfort levels with in-person communication in the library. The two genders show strikingly similar patterns in reported comfort levels, as shown in table 1 , where the answers "Definitely not" and "Probably not" were collapsed. The chi-square value was 2.619, which indicates that there is no relationship between gender and comfort level. Because of the strong similarity in men's and women's responses on this topic, they will be grouped together in all other sections of the discussion.
Table 1. "Are You More Comfortable Communicating with a Librarian in Person than by Chat, E-mail, or Phone?" Analyzed by Gender $\left(x^{2}=2.619, p>.05, d f=3\right)$

\begin{tabular}{llll}
\hline & Male & Female & Total \\
$\begin{array}{l}\text { Definitely not/ } \\
\text { probably not }\end{array}$ & $19(15.7 \%)$ & $11(9.6 \%)$ & $30(12.7 \%)$ \\
Maybe & $23(19.0 \%)$ & $19(16.5 \%)$ & $42(17.8 \%)$ \\
Probably & $43(35.5 \%)$ & $45(39.1 \%)$ & $88(37.3 \%)$ \\
Definitely & $36(29.8 \%)$ & $40(34.8 \%)$ & $76(32.2 \%)$ \\
\hline
\end{tabular}

\section{Awareness of Advertising}

Of the subjects, 153 (64.6 percent) reported that they had noticed at least one form of advertisement for UNC Libraries' reference services. These students were asked to mark all methods of advertising that they had seen. Many marked more than one. The remaining 84 students (35.4 percent) had not noticed any forms of advertisement. See table 2 for details. 


\section{History of Usage}

Students were asked whether they had used reference services (in-person or virtual) at any UNC library. Students who answered "yes" were asked which of a list of factors had encouraged them to use reference services. They were allowed to mark more than one factor. Eighty-three students (35 percent) reported having used these services already. Total use and breakdown by factor are shown in table 3.

Librarians have indirect but notable control over the top three factors. Strong extant relationships with faculty and other students lead to recommendations or requirements of using the reference desk. Simply making the desk welcoming and accessible also goes a long way.

Of factors over which librarians have direct control, the influence of discussing reference services during instruction sessions is the strongest. This is an encouraging statistic, as librarians can easily provide a brief introduction to these services, pass out any promotional materials (such as stickers displaying the Undergraduate Library's instant messenger screen name), and answer stu- dents' reference-related questions in only a few minutes.

Of the 194 students who had not learned about reference services during an instruction session, 60 (30.9 percent) had used reference services. (It is important to note that some of these students had not yet attended an instruction session at all, while others had attended an instruction session where the librarian did not discuss reference services. Others may simply not have remembered whether or not the librarian leading the session discussed reference.) However, of the 43 students who recalled a discussion of reference services, 23 (53.5 percent) had asked a question of a librarian. The chi-square test for this relationship provided a chi-square value of 7.873 , where $\mathrm{p}=0.005$ and $\mathrm{df}=1$. See figure 1 for percentages and raw figures.

This last insight highlights a great opportunity for library instructional staff. Verbally introducing reference services only needs to take a few minutes of classroom time. These few minutes can mark the beginning of many years of successful use of reference services and, by extension, better library usage overall.

Table 2. Advertising Methods Students Noticed in their First Semester (students were allowed to pick more than one)

\begin{tabular}{lcc}
\hline & Percentage of Subjects & Number of Subjects \\
Verbal pitch during an instruction session & 18.1 & 43 \\
“Ask A Librarian" link on a library webpage & 30.4 & 72 \\
Other verbal or visual advertisement & 37.1 & 88 \\
\hline
\end{tabular}

Table 3. Factors that Influenced Students to Use Reference Services (self-reported)

\begin{tabular}{lcc}
\hline & Percentage of Subjects & Number of Subjects \\
$\begin{array}{l}\text { Librarian mentioned services during } \\
\text { instruction session }\end{array}$ & 8.4 & 20 \\
$\begin{array}{l}\text { Noticed the “Ask A Librarian” link on a library } \\
\text { webpage }\end{array}$ & 6.8 & 16 \\
$\begin{array}{l}\text { Spoke with a librarian during orientation } \\
\text { Required by a professor or teaching assistant }\end{array}$ & 4.6 & 11 \\
$\begin{array}{l}\text { Recommended by a classmate or friend } \\
\text { Had used reference services at another library }\end{array}$ & 16.5 & 39 \\
Noticed the reference desk & 9.7 & 23 \\
Other & 4.6 & 11 \\
Total use & 11.8 & 28 \\
\hline
\end{tabular}




\section{DISCUSSION}

One important question the researcher had while working at the Undergraduate Library regarded the effectiveness of mentioning reference services during library instruction sessions. UNC's English department requires all sections of English 101 to hold at least one session at the library. However, since this survey was conducted in late September, many sections had not yet conducted their visit.

Figure 2 shows the relationship between learning about reference services during a session and feeling comfortable conducting reference interviews face-to-face. Notably, students who had learned about reference services during a library instruction session showed steadily increasing levels of confidence. Students who had not learned about reference services during a session peaked at "probably," then went down at the "definitely" level.

Figure 1. The relationship between learning about reference services during library instruction sessions and using reference services. $X 2=7.873, p=.005, d f=1$

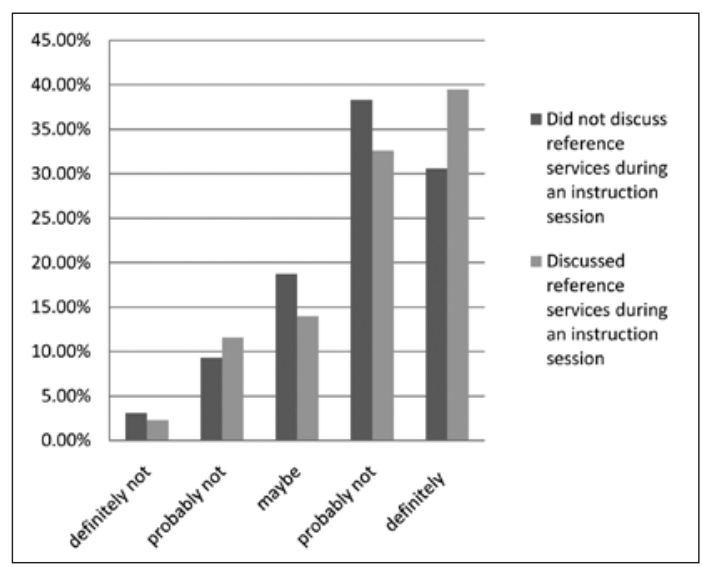

Figure 2. Does introducing reference services during instruction sessions encourage students to communicate with librarians in person? (Students were asked, "Are you more comfortable communicating with a librarian in person than by chat, e-mail, or phone?"

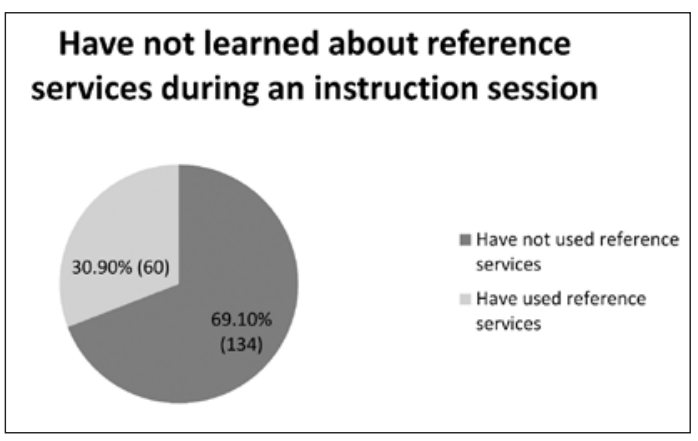

It is not necessarily advantageous for students to prefer an in-person reference contact. However, the role of the instruction sessions in increasing students' confidence in face-to-face interactions should be taken as a positive.

\section{Attitudes and Use of Reference Services}

One of the most striking sets of statistics in this study reflected students' confidence in librarians' willingness and abilities to help them with schoolwork. A total of 73.4 percent of students responded that librarians "probably" or "definitely" could help them with the majority of their questions. When the students who answered that librarians could "maybe" help are added, the total comes to 88.2 percent. These figures are especially interesting because the vast majority of students reported not having successfully received help at other libraries' reference desks. The overwhelmingly positive attitude seems either to reflect past positive interactions with librarians in other capacities or a quick development of positive attitudes during their first few weeks at UNC.

This pairing of information —attitudes and use levels-would be interesting to explore through a more extensive survey, a longitudinal study, or a comparison of underclassmen and upperclassmen. For instance, do students' expectations of the reference interactions closely match what actually happens? How many times do students need to interact with reference librarians to form a lasting personal research style that consistently includes consultation with librarians? Better understanding the connection between unsupported student attitudes and eventual interactions would help librarians plan to both work with students' expectations in mind and educate students about the possibilities of library assistance.

Examining students' attitudes toward librarians' capabilities to help raises the question of how many students actually request their help. The cross-tabulation of students' beliefs on this factor and their use of UNC University Libraries' reference services is shown in figure 3. Remember that although the majority of first-year students at UNC use the Undergraduate Library, use of reference services at any of the university's nineteen libraries counted for this study.

Interestingly, the differences in use are not significant. Several factors could play major roles. First, students may not have had a chance to act on their beliefs yet. Those who believe that a librarian could help them may not have needed to ask a research-related question yet.

Another possibility relates to the types of questions that students tend to ask at the librar- 
Figure 3. The relationship between students' beliefs on whether a librarian can answer their questions and actual usage of reference services. Students were asked, "Do you think that a librarian would be able to help you with most of the research- or school-related questions that you have?"

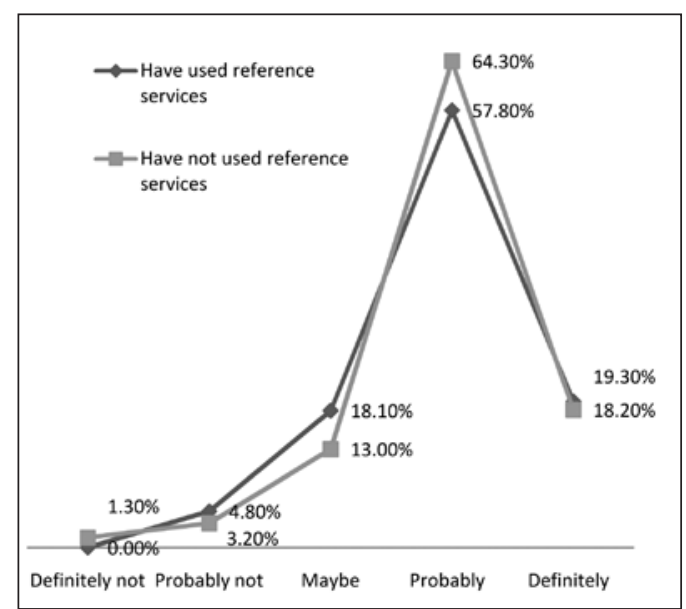

ies, especially at the beginning of their academic careers. Many may have asked librarians for help with things such as locating a building on campus. While this would relate to some degree of confidence in librarians' abilities, it would not necessarily connect with trust in their potential to answer academic questions. During the 2006-07 school year, the Undergraduate Library's reference desk recorded 8,971 questions. Of these, only 2,473 (27.6 percent) fell into the two categories most strongly related to schoolwork: research and citing information. ${ }^{31}$ That left a large proportion in the other categories: library information, building directional, campus information, computer/printer/ copier problems, reserves, the Media Resources Center, and miscellaneous. These students may not have perceived themselves as having a meaningful (or memorable) interaction with a librarian. However, assuming that the librarians successfully helped them with their information needs, these students were probably more comfortable with the idea of requesting a librarian's help than were their peers. Thus these interactions are indeed meaningful to the students' educational careers.

\section{LIMITATIONS}

This study has two notable limitations. First, the researcher's decision to survey more than one section taught by the same teaching assistant did decrease randomness. In UNC's English department, teaching assistants tend to teach several of the same class each semester. Most keep all of their sections on the same schedule. As a result, the teaching assistants who allowed surveying had either brought all or none of their sections to the library for an instruction session by the survey date. Comparing the potential statistical effects of increasing the sample size by several sections and increasing the randomness by limiting to one section per teaching assistant provided a challenge. Based on the advice of several experienced researchers at UNC's School of Information and Library Science, the author made the choice to go with the larger sample group.

Administering the survey very early in the semester limited applicability somewhat. Without further research, there is no way to know for certain how many first-year students would use reference services during a more extended period of time, such as their entire first semester and first year. Certainly that information would prove useful to academic librarians. However, the researcher was interested in seeing immediate results of early efforts to reach first-years. Schedule limitations precluded additional testing later in the semester.

\section{SUMMARY}

At least in their first year of college, students respond most strongly to library reference service promotions given in person. While conversations between first-years and library staff at orientation only left a small mark- 4.6 percent of students recalled these interactions-discussions held during instruction sessions held major sway over students' choices. First-year students also indicated a preference for face-to-face reference interactions. The combination of these two insights suggests that academic librarians should make a significant effort to reach out to freshmen in person, but that context is important. While the results from this research suggest that opportunities for extended interaction are among the most effective methods for encouraging future visits, librarians must balance this with time constraints and the need to have a presence at other events.

Virtual communication is still an important option in academic libraries. Students work from their dormitory rooms, travel the world, or sometimes just prefer communicating from the desk where they've settled to study in the library. However, often in-person communication is an option, and librarians and libraries must create many opportunities for it, both in the instruction lab and at the reference desk. 


\section{FUTURE RESEARCH}

This work provides numerous suggestions for future, related research. The most important may be exploring similar attitudes of upperclassmen. College students' information and research needs change throughout four or more years of school. They need to be reminded about ways librarians can help them and be encouraged to use the library in new ways. Consequently, insight on promotion to these more advanced students could significantly improve reference departments' outreach as well.

\section{References and Notes}

1. University of North Carolina News Services, "Compendium of Key Facts," www.unc.edu/news/compendium.shtml (accessed Nov. 7, 2007).

2. Totals provided by Suchi Mohanty, reference and instruction librarian at UNC's R. B. House Undergraduate Library.

3. Four-Year Colleges 2008 (Lawrenceville, N.J.: Peterson's, 2008); The Graduate School at the University of North Carolina, "About the Graduate School," http:// gradschool.unc.edu/about/about.html (accessed Nov. 3, 2007).

4. Four-Year Colleges 2008. The 34 percent average was calculated from Peterson's admissions data.

5. Ibid.

6. Department of English and Comparative Literature, "The Writing Program at UNC-Chapel Hill," http://english.unc.edu/comp/generalinformation.html (accessed Nov. 7, 2007).

7. Sharon L. Bostick, "The Development and Validation of the Library Anxiety Scale," (Ph.D. diss., Wayne State University, 1992), abstract in Dissertation Abstracts International, 53-12, A4116.

8. Anthony J. Onwuegbuzie, Qun G. Jiao, and Sharon L. Bostick, "Library Anxiety: Theory, Research, and Applications," Research Methods in Library and Information Studies, no. 1. (Lanham, Md.: Scarecrow, 2004).

9. Ibid.

10. Ibid., 35-36.
11. Joanne E. Callinan, "Information-Seeking Behaviour of Undergraduate Biology Students: A Comparative Analysis of First Year and Final Year Students in University College Dublin," Library Review 54, no. 2 (2005): 86-99.

12. Antony Brewerton, "Inspired! Award-Winning Library Marketing," New Library World 104, no. 7-8 (2003): 270.

13. Ibid., 267-77.

14. Ibid., 270.

15. Ruth Vondracek, "Comfort and Convenience? Why Students Choose Alternatives to the Library," portal: Libraries and the Academy 7, no. 3 (2007): 277-93.

16. Ibid., 281

17. Richard M. Dougherty, "Needed: User-Responsive Research Libraries," Library Journal 116, no. 1 (1991): 59-62, 60.

18. Marjorie E. Murfin, "Library Users and Reference Patrons," in The Reference Assessment Manual (Ann Arbor, Mich.: Pierian, 1995): 23-41.

19. Ibid.

20. Ibid., 24.

21. Lynn Silipigni Connaway, Marie L. Radford, and Timothy J. Dickey, "On the Trail of the Elusive Non-User: What Research in the Virtual Reference Environments Reveals," Bulletin of the American Society for Information Science \& Technology 34, no. 2 (2008): 25-28.

22. Ibid.

23. Ibid

24. Gayle Byerly, Annie Downey, and Lilly Ramin, "Footholds and Foundations: Setting Freshmen on the Path to Lifelong Learning," Reference Services Review 34, no. 4 (2006): 589-98.

25. Ibid., 591 .

26. Ibid., 595

27. Callinan, "Information-Seeking Behaviour of Undergraduate Biology Students."

28. Random numbers were selected using Mads Haahr, "Random Integer Generator," www.random.org/ integers (accessed Aug. 26, 2008).

29. Four-Year Colleges 2008.

30. College Board, 2007 College-Bound Seniors: State Report: North Carolina, www.collegeboard.com/prod_ downloads/about/news_info/cbsenior/yr2007/ NC_07.pdf (accessed Nov. 7, 2007).

31. Totals provided by Suchi Mohanty.

\section{APPENDIX: SURVEY TEXT}

Please complete the following questions whether or not you have used reference services at UNC-Chapel Hill's Libraries. Using reference services includes asking a research- or school-related question at the reference desk at one of UNC-Chapel Hill's libraries or asking reference librarians a question by Instant Messenger (buddy names undergradref or davisrefdesk), e-mail, or chat.

1. Gender:__male_female

2. Year at UNC-CH: _ first year__second year or beyond

3. Have you noticed any advertisements (verbal or visual) for UNC-Chapel Hill Libraries' reference services?

_.yes, in an instruction session

_ yes, on the library's website

_yes, somewhere else

_no, I have not noticed any 
4. Have you used reference services at UNC_Chapel Hill? __no _ yes

4a. If you answered yes, which of the following methods of promotion helped you become aware of reference services:

_ librarian mentioned it during a class visit to the library

_noticed the "Ask-a-Librarian" link on the Libraries' webpage: Askail I chat I phone | Im

_ spoke with a librarian or received promotional materials during orientation

_required by a professor/TA

_recommended by a classmate or friend

— had a good experience with reference services at another library in the past

_noticed the reference desk

_other (Please specify.):

5. Do you think that a librarian would be able to help you with most of the research- or school-related questions that you have?

_ definitely not

_probably not

_maybe

_probably

_definitely

6. Do you worry that the librarian will think you should know more than you do?

definitely not

_probably not

_maybe

_probably

_-definitely

7. Have librarians at this library or others usually been helpful with your research in the past?

_not at all helpful

_not very helpful

_no opinion

_a little bit helpful

_very helpful

8. Are you more comfortable communicating with a librarian in person than by chat, e-mail, or phone?

_definitely not

_-probably not

_maybe

_probably

_-definitely

9. How would you feel comfortable asking a librarian for research help? Please check all that apply.

by instant messenger

_ by a chat service run by the library

_by telephone

_by e-mail

_ _ in person during a group instruction session

_ _ in person at the reference desk

10. Anything else you'd like to tell us? 